\title{
Forecast and Opportunity Analysis of Cold Chain Logistics Demand of Fresh Agricultural Products under the Integration of Beijing, Tianjin and Hebei
}

\author{
Tongjuan Liu, Songmiao Li, Shaobo Wei \\ Information Institute, Beijing Wuzi University, Beijing, China \\ Email:1tj7905@163.com
}

How to cite this paper: Liu, T.J., Li, S.M. and Wei, S.B. (2017) Forecast and Opportunity Analysis of Cold Chain Logistics Demand of Fresh Agricultural Products under the Integration of Beijing, Tianjin and Hebei. Open Journal of Social Sciences, 5, 63-73.

https://doi.org/10.4236/jss.2017.510006

Received: June 5, 2017

Accepted: October 10, 2017

Published: October 13, 2017

\begin{abstract}
This paper is based on the national strategy of Beijing-Tianjin-Hebei integration. At first, we make strategy analysis on the development of cold chain logistics of fresh agricultural products, using the PEST analysis model to analyze the macro environment and SWOT analysis model to distinguish strengths, weaknesses, opportunities and threats it faced now meticulously, then we discuss the development strategy combination under the integration of the Beijing-Tianjin-Hebei region. Secondly, we analyze the cold chain logistics demand of fresh agricultural products in view of the integration of the Beijing-Tianjin-Hebei region under the fresh agricultural products categories. The exponential smoothing is used to forecast first, then the secondary exponential smoothing model is set up to make the fitting figure with the actual and predicted value. In addition, we forecast the output in the next few years and analyze the results. Finally, combining with the development strategy combination and prediction analysis, we put forward the development pattern and give a prospect of fresh agricultural products cold chain logistics.
\end{abstract}

\section{Keywords}

Beijing-Tianjin-Hebei Integration, Strategic Combination,

Demand Forecasting, Exponential Smoothing, Circulation System

\section{Introduction}

The Beijing-Tianjin-Hebei integration not only brings to the three regions economic benefits, but also stimulates the development of the industry capacity, in 
which the demand for fresh agricultural products rising, which makes cold chain logistics get a huge opportunity for development. So making an opportunity analysis and demand forecasting for fresh agricultural products cold chain logistics can promote the coordinated development of the Beijing-Tianjin-Hebei in cold chain logistics.

\section{Analysis on the Development Strategy of Cold Chain Logistics of Fresh Agricultural Products under the Integration of Beijing-Tianjin-Hebei}

\subsection{PEST Analysis on the Development of Cold Chain Logistics of Fresh Agricultural Products in the Beijing-Tianjin-Hebei Region}

1) Policy analysis

In 2016, the Ministry of Agriculture and other departments jointly issued the "Beijing-Tianjin-Hebei agricultural products circulation system innovation action plan". The 13th five-year plan points out that "we need to vigorously develop cold chain logistics". The strategy of the Beijing-Tianjin-Hebei cooperation, is a long-term plan that needs to be completed in three areas [1].

2) Economic analysis

On the macro level, the economic development level in the Beijing-TianjinHebei region is relatively high, the GDP reached 6935.889 billion yuan in 2015, accounting for 10.16 percent of the country's GDP. The following is a comparison in 2015 (see Table 1).

Micro-point of view, the sufficient production of six kinds of fresh agricultural products in the three regions together creates a prerequisite for the development of cold chain logistics (see Table 2). To analyze and forecast the cold chain logistics demand of fresh agricultural products can achieve a reasonable allocation of resources [2].

3) Social analysis

With the consumption of fresh agricultural products gradually increase, the relevant storage and end sales of cold chain logistics demand is also increasing as people pay more attention to food quality and safety [3]. The emergence of fresh

Table 1. A comparison of the total economic aggregate of the Beijing-Tianjin-Hebei region in 2015.

\begin{tabular}{ccccccccc}
\hline Region & GDP & $\begin{array}{c}\text { Per } \\
\text { capita } \\
\text { GDP }\end{array}$ & $\begin{array}{c}\text { The added } \\
\text { value of } \\
\text { primary } \\
\text { industry }\end{array}$ & $\begin{array}{c}\text { The added } \\
\text { value of } \\
\text { secondary } \\
\text { industry }\end{array}$ & $\begin{array}{c}\text { The added } \\
\text { value of } \\
\text { tertiary } \\
\text { industry }\end{array}$ & $\begin{array}{c}\text { The proportion } \\
\text { of added value } \\
\text { of each industry (\%) }\end{array}$ \\
\hline Beijing & $23,014.59$ & $106,497.0$ & 140.21 & 4542.64 & $18,331.74$ & 0.61 & 19.74 & 79.65 \\
Tianjin & $16,538.19$ & $107,960.0$ & 208.82 & 7704.22 & 8625.15 & 1.26 & 46.58 & 52.15 \\
Hebei & $29,806.11$ & $40,255.0$ & 3439.45 & $14,386.87$ & $11,979.79$ & 11.54 & 48.27 & 40.19 \\
total & $69,358.89$ & $254,712.0$ & 3788.48 & $26,633.73$ & $38,936.68$ & 5.46 & 38.40 & 56.14 \\
\hline
\end{tabular}

a Source: Yearbook 2015, for the Beijing-Tianjin-Hebe Region. 
Table 2. The output of major agricultural products in the Beijing-Tianjin-Hebei region in 2016.

\begin{tabular}{ccccccc}
\hline Region & Vegetables & Fruit & Meat & Milk & Eggs & $\begin{array}{c}\text { Aquatic } \\
\text { products }\end{array}$ \\
\hline Beijing & 183.60 & 69.61 & 37.04 & 45.70 & 18.30 & 7.13 \\
Tianjin & 453.36 & 59.20 & 45.45 & 68.02 & 20.63 & 40.18 \\
Hebei & 8193.37 & 1524.59 & 457.67 & 388.54 & 448.04 & 132.17 \\
Total & 8830.33 & 1653.40 & 540.16 & 502.26 & 486.97 & 179.48 \\
\hline
\end{tabular}

e-commerce has also accelerated the demand for cold chain logistics. According to the statistics, China has over 90 billion yuan of fresh e-commerce transactions in 2016.

4) Technical analysis

Statistics show that, there are about 900 professional refrigerated vehicles in Hebei province, about 2800 temperature control processing and sorting facilities. In addition, Tianjin is to speed up the modernization construction of cold storage, more than 40 existing refrigerator.

\subsection{SWOT Analysis on the Development of Cold Chain Logistics of Fresh Agricultural Products in the Beijing-Tianjin-Hebei Region}

1) Strength analysis

a) Market potential is huge

The consumption of agricultural products is increasing in three areas. As shown in Figure 1, the demand for these six types of fresh agricultural products has also increased steadily for nearly six years; we can make a conclusion that this high demand for fresh agricultural products may lead to a high claim for cold chain logistics.

b) Three District traffic integration

The Integration of the Beijing-Tianjin-Hebei region starts with the implementation of the construction of the traffic integration. The three-dimensional convenient transportation system makes the logistics industry more prosperous.

2) Weakness analysis

a) Low degree of informatization

It is found that there is lack of unified cold chain logistics information sharing platform to manage the huge information. The informatization level was $90 \%$, only play a role in controlling the temperature and preservation in the process of cold chain transportation.

b) Cold chain logistics facilities lag behind

At present, China's cold chain logistics transport infrastructure is relatively old, logistic facilities in the coastal cities are more complete than in the inland city. There are only 6970 railway refrigerated trucks accounting for two percent of the total running vehicles. 


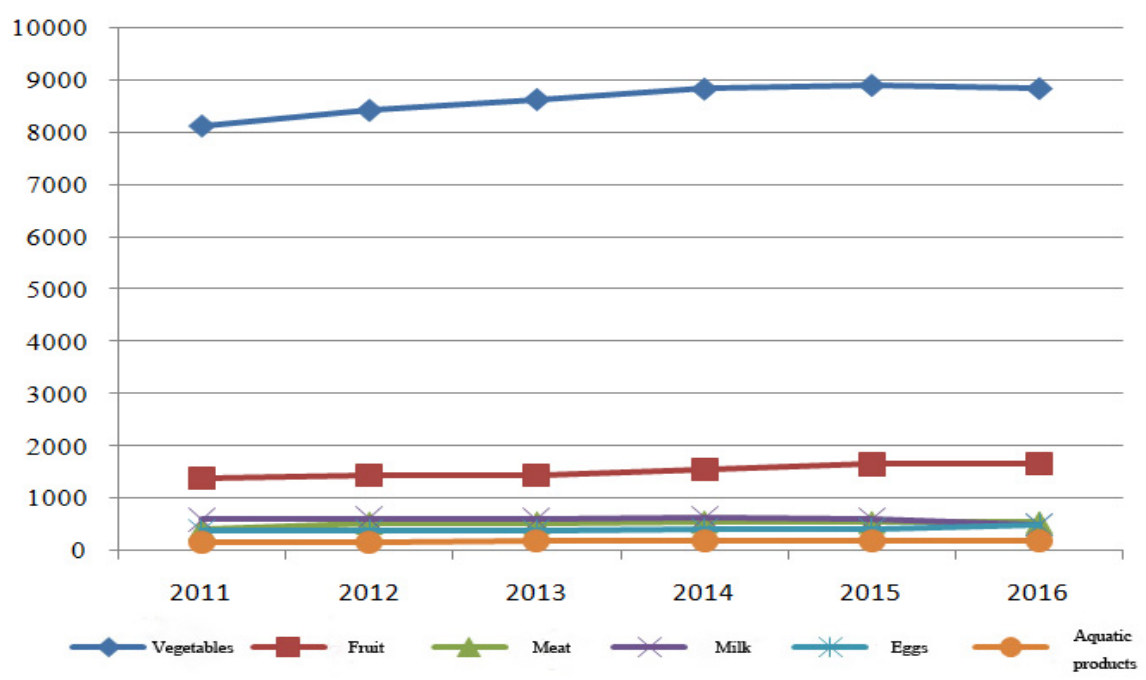

Figure 1. The output of agricultural products in the Beijing-Tianjin-Hebei region in recent six years.

3) Opportunity analysis

a) Government support

The Ministry of Transport said that eight major projects in the Beijing-Tianjin-Hebei region will be promoted in 2016, including promote the construction of highway projects and form the modern port cluster.

b) The demand for cold chain logistics is increasing

According to the data, China has been reaching more than 100 million tons of cold chain demand scale in 2015 and maintaining the growth rate of about $15 \%$ of the cold chain logistics market. The total population of the Beijing-TianjinHebei region has exceeded 100 million. It is conceivable that the demand for cold chain logistics will rise.

4) Threat analysis

a) Lack of international competitiveness

In recent years, many international famous logistics enterprises enter the Chinese market. It is a growing threat because China is lack of international competitiveness.

b) Cold chain logistics input cost is high, the risk is big

Cold chain logistics market has a higher threshold and a higher cost of investment compared to other logistics market. In order to keep the freshness of fresh agricultural products, the operation emphasizes that each process is interlocking and the risk is high.

\subsection{The Strategic Combination of Cold Chain Logistics Development of Fresh Agricultural Products in the Beijing-Tianjin-Hebei Region}

1) Increase the construction of infrastructure

In the face of the competition in the cold chain logistics market, the government should increase investment in cold chain logistics infrastructure equip- 
ment, improving or introducing equipment, coupled with reasonable use and management.

2) Establish a perfect cold chain logistics system

The Beijing-Tianjin-Hebei region should strengthen the cold chain logistics information communication and sharing, and jointly establish a perfect cold chain logistics system, which can achieve the entire cold chain logistics monitoring and management.

3) Vigorously develop the third party cold chain logistics

Improving the third party logistics enterprise's development will greatly improve the efficiency of cold chain logistics in our country. At the same time, outsourcing of logistics activities is beneficial to the enterprises to focus on the core business.

\section{Analysis on the Demand of Cold Chain Logistics of Fresh Agricultural Products under the Integration of Beijing, Tianjin and Hebei}

According to the data, the output of these six kinds of agricultural products in Beijing (see Table 3), Tianjin (see Table 4), Hebei Province (see Table 5) in 2011-2016 are as follows respectively.

Table 3. The output of Agricultural Products in Beijing from 2011 to 2016.

\begin{tabular}{ccccccc}
\hline Years & Vegetables & Fruit & Meat & Milk & Eggs & $\begin{array}{c}\text { Aquatic } \\
\text { products }\end{array}$ \\
\hline 2011 & 296.90 & 87.80 & 44.40 & 64.00 & 15.10 & 6.10 \\
2012 & 279.90 & 84.30 & 43.20 & 65.10 & 15.20 & 6.40 \\
2013 & 266.90 & 79.50 & 41.80 & 61.50 & 17.50 & 6.40 \\
2014 & 236.20 & 74.50 & 39.30 & 59.50 & 19.70 & 6.80 \\
2015 & 205.10 & 71.40 & 36.40 & 57.20 & 19.60 & 8.20 \\
\hline
\end{tabular}

Table 4. The output of agricultural products in Tianjin from 2011 to 2016.

\begin{tabular}{ccccccc}
\hline Years & Vegetables & Fruit & Meat & Milk & Eggs & $\begin{array}{c}\text { Aquatic } \\
\text { products }\end{array}$ \\
\hline 2011 & 444.23 & 61.58 & 42.98 & 69.09 & 18.65 & 35.21 \\
2012 & 445.41 & 59.91 & 45.80 & 67.87 & 18.66 & 35.94 \\
2013 & 455.06 & 54.17 & 46.48 & 68.24 & 18.89 & 39.86 \\
2014 & 460.20 & 62.70 & 46.40 & 68.90 & 19.80 & 40.80 \\
2015 & 441.54 & 62.69 & 45.75 & 68.00 & 20.20 & 40.10 \\
\hline
\end{tabular}


Table 5. The output of agricultural products in Hebei from 2011 to 2016.

\begin{tabular}{ccccccc}
\hline Years & Vegetables & Fruit & Meat & Milk & Eggs & $\begin{array}{c}\text { Aquatic } \\
\text { products }\end{array}$ \\
\hline 2011 & 7384.30 & 1238.69 & 329.50 & 458.90 & 339.80 & 106.71 \\
2012 & 7695.10 & 1286.00 & 442.90 & 479.00 & 342.60 & 116.30 \\
2013 & 7902.10 & 1303.10 & 448.80 & 465.70 & 346.10 & 123.10 \\
2014 & 8125.70 & 1420.60 & 468.10 & 496.10 & 362.70 & 126.40 \\
2015 & 8243.70 & 1508.60 & 462.50 & 480.90 & 373.60 & 129.30 \\
2016 & 8193.37 & 1524.59 & 457.67 & 388.54 & 448.04 & 132.17 \\
\hline
\end{tabular}

\subsection{Prediction Method of Cold Chain Logistics Demand for Fresh Agricultural Products [4]}

This paper takes the exponential smoothing method proposed by Robert G. Brown, which builds a secondary exponential smoothing model based on an exponential smoothing, making the data more reliable.

The exponential smoothing formula is

$$
S_{t}^{(1)}=\alpha Y_{t}+(1-\alpha) S_{t-1}^{(1)}
$$

$Y_{i}$ : The actual value of $\mathrm{t}$ period

$S_{t}^{(1)}$ : the predicted value of $\mathrm{t}$ period

$S_{t-1}{ }^{(1)}$ : the predicted value of the $t-1$ period

$\alpha$ : the smoothing exponent

The secondary exponential smoothing formula is

$$
S_{t}^{(2)}=\alpha S_{t}+(1-\alpha) S_{t-1}^{(2)}
$$

$S_{t}^{(2)}$ : the second exponential smoothing value of $\mathrm{t}$ period

$S_{t-1}{ }^{(2)}$ : the second exponential smoothing value of $t-1$ period

The quadratic exponential smoothing model is

$$
\begin{gathered}
Y_{(t+T)}=A_{t}+B_{t} * T \\
A_{t}=2 S_{t}^{(1)}-S_{t}^{(2)} \\
B_{t}=[\alpha /(1-\alpha)] *\left[S_{t}^{(1)}-S_{t}^{(2)}\right]
\end{gathered}
$$

\subsection{Prediction of Cold Chain Logistics Demand for Fresh Agricultural Products under the Single Smoothing Method}

We use the exponential smoothing method to forecast the yield of all kinds of fresh agricultural products in the three places, the most critical step is to determine the value of the smoothing coefficient $\alpha$, the values of $\alpha$ are $0.1,0.3,0.5$ and 0.9 respectively, and the predicted values of the demand for the fresh agricultural products with the four smoothing coefficients are calculated. And then compare the error size between predicted value and actual value, and select the smoothing factor in the case of minimum error, and use it for the secondary exponential smoothing. 
1) Prediction of Cold Chain Logistics Demand for Fresh Agricultural Products under the Single Exponential Smoothing Method in Beijing.

The following is the cold chain demand based on the data of the poultry egg production during 2011-2010 in Beijing (see Table 6).

Similarly, using the method mentioned above, we can identify that the smoothing coefficients of vegetables, fruits, meat, milk, eggs and aquatic products in Beijing were as follows: Vegetables: $\alpha=0.9$; Fruit: $\alpha=0.9$; Meat: $\alpha=0.9$; milk: $\alpha=0.5$; eggs: $\alpha=0.9$; aquatic products: $\alpha=0.9$.

2) Prediction of Cold Chain Logistics Demand for Fresh Agricultural Products under the Single Smoothing Method in Tianjin and Hebei.

In the same way, using the method mentioned above, we can also get the smoothing coefficients in Tianjin respectively: Vegetables: $\alpha=0.1$; Fruit: $\alpha=0.1$; Meat: $\alpha=0.3$; milk: $\alpha=0.1$; eggs: $\alpha=0.9$; aquatic products: $\alpha=0.9$. What is more, Just like the two regions, the smoothing coefficients in Hebei were as follows: Vegetable: $\alpha=0.9$; Fruit: $\alpha=0.9$; Meat: $\alpha=0.9$ : milk: $\alpha=0.1$; eggs: $\alpha=0.9$; aquatic products: $\alpha=0.9$.

\subsection{Prediction of Cold Chain Logistics Demand for Fresh Agricultural Products under the Secondary Exponential Smoothing Method}

According to the exponential smoothing method, the corresponding smoothing coefficient $\alpha$ of each kind of fresh agricultural products is selected for the second smoothing prediction. Based on the results of the secondary exponential smoothing and the actual value, the fitting situation is observed and the proposed model is used to forecast the sales of various agricultural products from 2017 to 2021.

1) Prediction of Cold Chain Logistics Demand for Fresh Agricultural Products under the Secondary Exponential Smoothing Method in Beijing.

Based on the secondary exponential smoothing method, the forecast sales of poultry eggs and the demand volume of cold chain logistics in Beijing in the past

Table 6. The forecast demand and error of Beijing egg cold chain logistics by the single smoothing method.

\begin{tabular}{ccccccccccc}
\hline \multirow{2}{*}{ Years } & \multirow{2}{*}{$\begin{array}{l}\text { Actual } \\
\text { output }\end{array}$} & \multicolumn{3}{c}{ Predicted value } & \multicolumn{5}{c}{ Absolute error } \\
\cline { 3 - 10 } & & $\alpha=0.1$ & $\alpha=0.3$ & $\alpha=0.5$ & $\alpha=0.9$ & $\alpha=0.1$ & $\alpha=0.3$ & $\alpha=0.5$ & $\alpha=0.9$ \\
\hline 2011 & 15.10 & 15.93 & 15.93 & 15.93 & 15.93 & 0.83 & 0.83 & 0.83 & 0.83 \\
2012 & 15.20 & 15.85 & 15.68 & 15.52 & 15.18 & 0.65 & 0.48 & 0.32 & 0.02 \\
2013 & 17.50 & 15.79 & 15.54 & 15.36 & 15.20 & 1.72 & 1.96 & 2.14 & 2.30 \\
2014 & 19.70 & 15.96 & 16.13 & 16.43 & 17.27 & 3.74 & 3.57 & 3.27 & 2.43 \\
2015 & 19.60 & 16.33 & 17.20 & 18.06 & 19.46 & 3.27 & 2.40 & 1.54 & 0.14 \\
2016 & 18.30 & 16.66 & 17.92 & 18.83 & 19.59 & 1.64 & 0.38 & 0.53 & 1.29 \\
total & & & & & & 11.85 & 9.63 & 8.63 & 7.01 \\
average & & & & & & 1.98 & 1.61 & 1.44 & 1.17 \\
\hline
\end{tabular}


6 years (see Table 7). According to the actual value of Beijing egg sales and the forecast value of cold chain logistics demand in the past 6 years, as shown in Figure 2.

From Figure 2, we can observe that the fitting relationship is very good between the predicted value and the actual value. Therefore, we can use this method to predict the poultry eggs sales and cold chain logistics demand in the next five years in Beijing (see Table 8).

Similarly, we can predict the six categories of products' demand in the next five years in Beijing by using the smoothing coefficients they have. As shown in Table 9 below.

2) Prediction of Cold Chain Logistics Demand for Fresh Agricultural Products under the Secondary Exponential Smoothing Method in Tianjin and Hebei.

Respectively, using the same method, we can get the forecast sales and the demand in the next five years in Tianjin (see Table 10) and Hebei (see Table 11).

Table 7. Beijing egg sales and cold chain logistics demand in recent six years.

\begin{tabular}{ccc}
\hline Years & Actual value & Predicted value \\
\hline 2011 & 15.10 & 15.93 \\
2012 & 15.20 & 15.26 \\
2013 & 17.50 & 15.20 \\
2014 & 19.70 & 17.06 \\
2015 & 19.60 & 19.22 \\
2016 & 18.30 & 19.55 \\
\hline
\end{tabular}

Table 8. Forecast of sales and cold chain logistics demand for eggs in Beijing in the next five years.

\begin{tabular}{lc}
\hline Years & Predicted value \\
\hline 2017 & 19.954 \\
2018 & 20.285 \\
2019 & 20.616 \\
2020 & 20.948 \\
2021 & 21.279 \\
\hline
\end{tabular}

Table 9. Forecast of sales and cold chain logistics demand for six kinds of agricultural products in Beijing in the next five years.

\begin{tabular}{ccccccc}
\hline Years & $\begin{array}{c}\text { Vegetables } \\
\alpha=0.9\end{array}$ & $\begin{array}{c}\text { Fruit } \\
\alpha=0.9\end{array}$ & $\begin{array}{c}\text { Meat } \\
\alpha=0.9\end{array}$ & $\begin{array}{c}\text { Milk } \\
\alpha=0.5\end{array}$ & $\begin{array}{c}\text { Eggs } \\
\alpha=0.9\end{array}$ & $\begin{array}{c}\text { Aquatic } \\
\text { products } \\
\alpha=0.9\end{array}$ \\
\hline 2017 & 174.610 & 64.707 & 34.758 & 56.065 & 19.954 & 7.458 \\
2018 & 144.081 & 59.807 & 32.482 & 54.489 & 20.285 & 7.788 \\
2019 & 113.552 & 54.907 & 30.205 & 52.913 & 20.616 & 8.119 \\
2020 & 83.023 & 50.007 & 27.928 & 51.337 & 20.948 & 8.450 \\
2021 & 52.494 & 45.107 & 25.651 & 49.761 & 21.279 & 8.780 \\
\hline
\end{tabular}




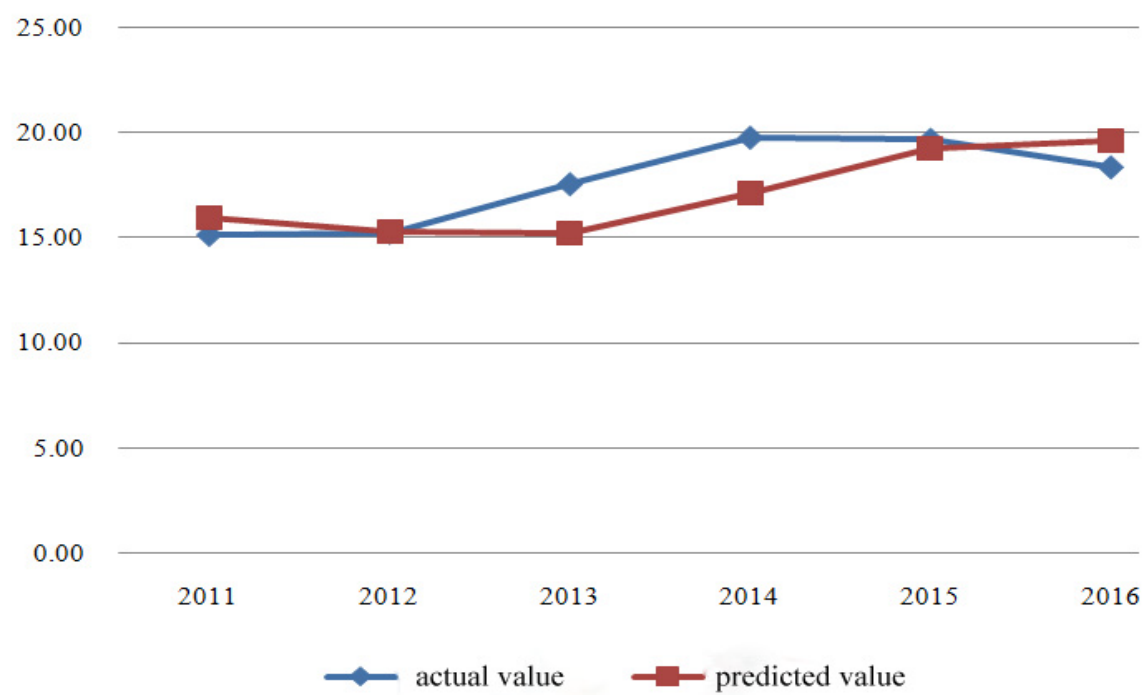

Figure 2. Fitting diagram of sales and predicted value of eggs in secondary exponential smoothing method $(\alpha=0.9)$.

Table 10. Forecast of sales and cold chain logistics demand for six kinds of agricultural products in Tianjin in the next five years.

\begin{tabular}{ccccccc}
\hline Years & $\begin{array}{c}\text { Vegetables } \\
\alpha=0.1\end{array}$ & $\begin{array}{c}\text { Fruit } \\
\alpha=0.1\end{array}$ & $\begin{array}{c}\text { Meat } \\
\alpha=0.3\end{array}$ & $\begin{array}{c}\text { Milk } \\
\alpha=0.1\end{array}$ & $\begin{array}{c}\text { Eggs } \\
\alpha=0.9\end{array}$ & $\begin{array}{c}\text { Aquatic } \\
\text { products } \\
\alpha=0.9\end{array}$ \\
\hline 2017 & 449.163 & 59.233 & 46.160 & 68.388 & 20.681 & 39.803 \\
2018 & 449.206 & 59.263 & 46.302 & 68.387 & 21.158 & 39.486 \\
2019 & 449.250 & 59.293 & 46.444 & 68.386 & 21.635 & 39.168 \\
2020 & 449.294 & 59.323 & 46.586 & 68.385 & 22.112 & 38.850 \\
2021 & 449.337 & 59.353 & 46.727 & 68.384 & 22.589 & 38.532 \\
\hline
\end{tabular}

Table 11. Forecast of sales and cold chain logistics demand for six kinds of agricultural products in Hebei in the next five years.

\begin{tabular}{ccccccc}
\hline Years & $\begin{array}{c}\text { Vegetables } \\
\alpha=0.9\end{array}$ & $\begin{array}{c}\text { Fruit } \\
\alpha=0.9\end{array}$ & $\begin{array}{c}\text { Meat } \\
\alpha=0.9\end{array}$ & $\begin{array}{c}\text { Milk } \\
\alpha=0.1\end{array}$ & $\begin{array}{c}\text { Eggs } \\
\alpha=0.9\end{array}$ & $\begin{array}{c}\text { Aquatic } \\
\text { products } \\
\alpha=0.9\end{array}$ \\
\hline 2017 & 8382.460 & 1599.569 & 461.817 & 475.396 & 385.241 & 132.388 \\
2018 & 8520.189 & 1690.438 & 460.887 & 475.760 & 396.853 & 135.464 \\
2019 & 8657.917 & 1781.306 & 459.957 & 476.124 & 408.464 & 138.540 \\
2021 & 8795.646 & 1872.175 & 459.027 & 476.488 & 420.075 & 141.617 \\
\hline
\end{tabular}

\subsection{Predictive Results Analysis}

Summarize the forecast analysis above, the forecast sales of various agricultural products in the Beijing-Tianjin-Hebei region in the period of 2017-2021 areas 
shown in Table 12. Coupled with the yield of various agricultural products in the Beijing-Tianjin-Hebei region during 2011-2016, this paper analyzes the trend of agricultural products sales in the Beijing-Tianjin-Hebei region in the recent 10 years, as shown in Figure 3.

As we can see from the Figure 3, the overall demand of fresh agricultural products show a steady upward trend in the Beijing-Tianjin-Hebei region. This requires flexibility and timeliness in cold chain logistics and it is necessary to make the cold chain logistics bigger and stronger during the period of integration.

\section{Conclusion}

In the 21st century, Beijing, Tianjin and Hebei are actively responding to the ever-changing industry environment and adapting to the environment to make targeted measures to the cold chain logistics system. Through the PEST and SWOT analysis, we put forward the development strategic combination of cold chain logistics. Through fresh agricultural products demand forecasting analysis

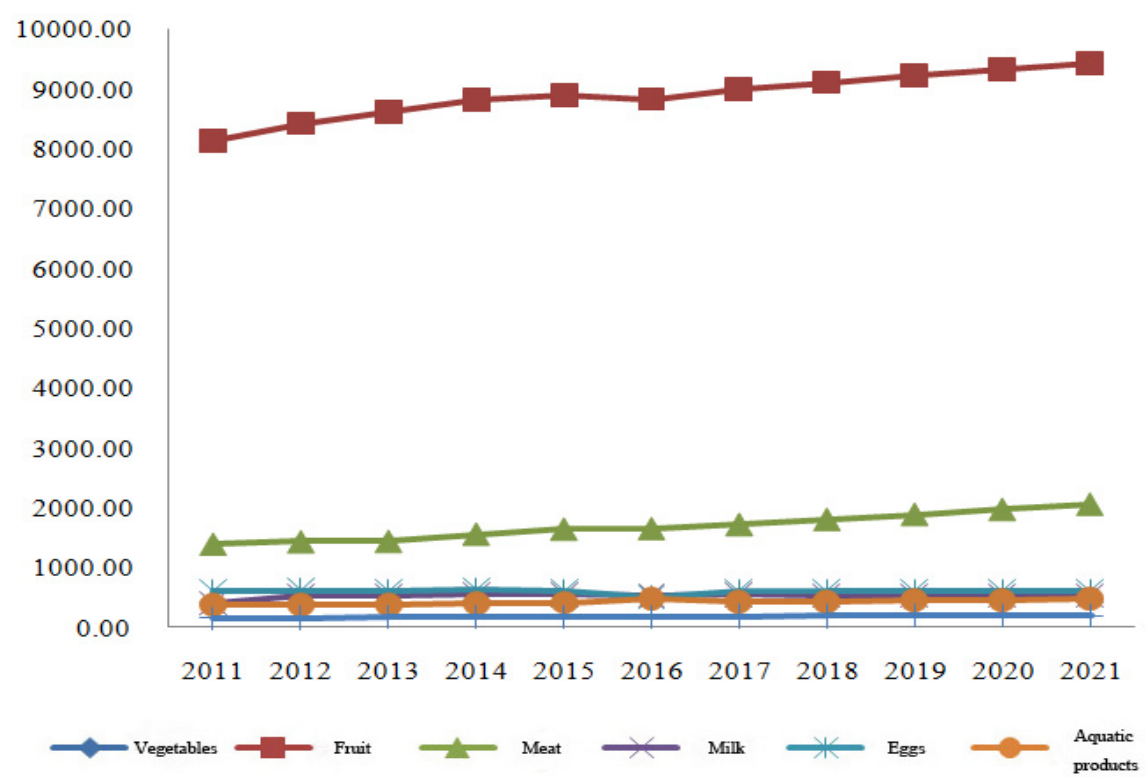

Figure 3. Sales trend of agricultural products in the Beijing-Tianjin-Hebei region.

Table 12. Forecast of sales and cold chain logistics demand of six kinds of agricultural products in the Beijing-Tianjin-Hebei region in the next five years.

\begin{tabular}{ccccccc}
\hline Years & Vegetables & Fruit & Meat & Milk & Eggs & $\begin{array}{c}\text { Aquatic } \\
\text { products }\end{array}$ \\
\hline 2017 & 9006.233 & 1723.509 & 542.736 & 599.849 & 425.876 & 179.649 \\
2018 & 9113.476 & 1809.507 & 539.671 & 598.636 & 438.295 & 182.738 \\
2019 & 9220.719 & 1895.506 & 536.606 & 597.423 & 450.715 & 185.827 \\
2020 & 9327.963 & 1981.505 & 533.541 & 596.209 & 463.134 & 188.916 \\
2021 & 9435.206 & 2067.503 & 530.475 & 594.996 & 475.553 & 192.006 \\
\hline
\end{tabular}


in the next five years in the Beijing-Tianjin-Hebei region, we know that the sales rose slightly, and we also affirm that the necessity to develop the cold chain logistics under the integration situation.

The economic positioning of the three districts is different and the industrial layout and urban planning in the three regions are inconsistent. This inconsistency can also lead to inconsistencies in the flow and direction of the cold chain logistics. The best solution is to form a circulating system of the Beijing-Tianjin-Hebei region. Moreover, the integration will make good use of the comparative advantages of the regions to form a fixed time fresh agricultural products logistics circle around Beijing, Tianjin and Hebei, so as to construct an efficient food cold chain distribution system, which is beneficial to drive the sale of fresh agricultural products. At the same time, it can provide reference for the government to plan the logistics parks and investors to invest in the cold chain industry of local fresh agricultural products. Therefore, it is promising to develop cold chain logistics of fresh agricultural products under the integration of Beijing, Tianjin and Hebei.

\section{Acknowledgements}

This work was supported by funding project for Youth Talent Cultivation Plan of Beijing City University Under the grant number (CIT \& TCD201504051), Beijing Key Laboratory (NO:BZ0211) and Beijing Intelligent Logistics System Collaborative Innovation Center.

\section{References}

[1] Zhao, Y.J., Wang, S.J., Su, Y.N. and Dai, Y.Y. (2015) SWOT Analysis of "Agricultural Super-Docking” in Hebei Province under the Coordinated Development of Beijing-Tianjin-Hebei. Logistics Technology, 4, 32-33.

[2] Zhao, R. (2016) A SWOT Analysis and Countermeasures for the Coordinated Development of Regional Economic and Regional Logistics in Beijing-Tianjin-Hebei Region. Logistics Technology, 35, 41-43.

[3] Wang, X.H., Zong, Y.S. Wang, G.B. and Ding, L.F. (2013) Agricultural Cold Chain Logistics Demand Impetus and Development Strategies in Shanxi Province. Journal of Shanxi Agricultural Science, 9, 1400-1404.

[4] Jiang, L.L. (2013) Study on Cold Chain Logistics Model of Agricultural Products in Hebei Province Based on Demand Analysis. Thesis, Hebei Normal University, Hebei. 